\title{
Modulation by caffeine of calcium-release microdomains in frog skeletal muscle fibers
}

\author{
JULIO L VERGARA and MARINO DIFRANCO
}

Department of Physiology, David Geffen School of Medicine, University of California at Los Angeles (UCLA), Los Angeles, CA, USA.

\begin{abstract}
The effects of caffeine on the process of excitation-contraction coupling in amphibian skeletal muscle fibers were investigated using the confocal spot detection technique. This method permits to carefully discriminate between caffeine effects on the primary sources of $\mathrm{Ca}^{2+}$ release at the Z-lines where the triads are located and secondary actions on other potential Ca Release sources. Our results demonstrate that $0.5 \mathrm{mM}$ caffeine potentiates and prolongs localized action-potential evoked $\mathrm{Ca}^{2+}$ transients recorded at the level of the Z-lines, but that $1 \mathrm{mM}$ only prolongs them. The effects at both doses are reversible. At the level of the M-line, localized $\mathrm{Ca}^{2+}$ transients displayed more variability in the presence of $1 \mathrm{mM}$ caffeine than in control conditions. At this dose of caffeine, extra-junctional sources of $\mathrm{Ca}^{2+}$ release also were observed occasionally.
\end{abstract}

Key terms: excitation-contraction coupling, caffeine, confocal spot detection, calcium transients, frog skeletal muscle, calcium microdomains.

\section{PREFACE}

Although Eduardo (Guayo) Rojas was the mentor of only one of the authors of this paper (JLV), his reverence for experimental biophysics has been a legacy passed from generation to generation. Thus, it seems fitting that both authors dedicate this article containing unpublished data to Guayo as a modest token of our appreciation for his love for the inherent beauty of the "unexpected."

But before getting into the scientific section of the work, the authors would like to include in this publication a summary of an introduction to a talk presented October 29, 2002 by JLV in La Serena, Chile, on the occasion of a symposium honoring Eduardo's valuable scientific contributions:

"A few days ago, I was interviewed by a group of high-school students who were preparing a video documentary about the Laboratorio de Fisiologia y Biofisica de Montemar, where I had the privilege to work in my Ph.D. thesis. Among the very insightful questions from the students, one of them asked me: What was the impact that the experience at Montemar had on your life as a scientist and as a person? After a prolonged period of reflection (this was not an easy question to answer), I could only come up with only one spontaneous answer: it made my life! Indeed, it made my life, and I would like to share with you the most important reasons why it did so:

First and foremost, it allowed me to meet and to become really close (perhaps too close, almost like siblings) to two people whom I admire deeply, Guayo and Illani. Our life together during those early years in Montemar went far beyond that of the formal, sometimes cold, student-teacher relationship that I had seen in the University before. On the contrary, my life as a graduate student was one of constant argumentation (mostly about scientific matters) with my advisor. Guayo's leadership forced me to really think about issues and to understand that science is to be lived! 
The second reason why Montemar made my life is because at an early stage in my career, I lost the fear of the big problems and the big names in science. My Montemar experience, strongly reinforced by Eduardo's irreverence, taught me that only the big problems in science are worth our efforts and that big names are only guys who were there before us. Indeed, Guayo allowed me to corroborate these principles on many occasions. For example, one weekend only three months after my arrival in Montemar, he went to Santiago and left me in charge of hosting none other than Kenneth S. Cole, Robert (Bob) Taylor, Richard D. Keynes, and his wife, Ann. Needless to say, I still have nightmares about my performance in that occasion, but I indeed recognize that it was a crash course in irreverence.

The third reason why the Montemar experience made my life is relevant to this talk [and the paper below]: I came in touch with a scientific problem that has obsessed me since then, the role of the membrane potential on the $\mathrm{Ca}^{2+}$ regulation in muscle".

\section{INTRODUCTION}

A critical step in the excitation-contraction (EC) coupling process in skeletal muscle is the release of $\mathrm{Ca}^{2+}$ ions, stored at a high concentration in the lumen of the terminal cisternae (TC) of the sarcoplasmic reticulum (SR), in response to electrical depolarization of the transverse tubular system (Peachey, 1965). The structures supporting this $\mathrm{Ca}^{2+}$ release phase of EC coupling are proposed to be regions of the SR adjacent to the transverse tubule (Ttubule), known as T-SR junctions, where $\mathrm{Ca}^{2+}$ release channels (ryanodine receptor channels, RyR) and voltage sensors (dihydropyridine receptors, DHPRs) are presumed to be linked through proteinprotein interactions (Rios and Pizarro, 1991). In frog skeletal muscle fibers, the TSR junctions are remarkably well aligned with the Z-lines delimiting every sarcomere (Peachey, 1965; Kim and Vergara, 1998). Consequently, it is expected that, in this preparation, action potentials (APs) generate early increases in the $\mathrm{Ca}^{2+}$ concentration $\left(\left[\mathrm{Ca}^{2+}\right]\right)$ at regions of the sarcomere close to the Z-line and smaller and more delayed changes at more remote regions (M-lines).

The localization of the sites of $\mathrm{Ca}^{2+}$ release at the Z-lines was first demonstrated experimentally by Escobar et al. (1994) using a spot detection method and fluorescent $\mathrm{Ca}^{2+}$ indicators. These authors also observed that, in amphibian muscle fibers, the AP-elicited $\left[\mathrm{Ca}^{2+}\right]$ increase at the $\mathrm{M}$-line was not delayed significantly relative to that at the $\mathrm{Z}$-line ( $\mathrm{Z}-\mathrm{M}$ delay) and proposed that a broad band of the SR may participate in the release process (Escobar et al., 1994). This suggestion was confirmed in experiments that incorporated technical refinements to the spot detection method (DiFranco et al., 2002) and with quantitative modeling of the diffusion-reaction process involved in the $\mathrm{Ca}^{2+}$ redistribution within the sarcomere (Novo et al., 2003). The underlying mechanisms by which $\mathrm{Ca}^{2+}$ ions released from one region of the SR may lead to activation of the release of additional $\mathrm{Ca}^{2+}$ from neighboring regions are not fully understood, but they can, for example, involve the positive feedback process known as $\mathrm{Ca}$-induced $\mathrm{Ca}^{2+}$-release (CICR, Endo et al., 1970; Fabiato and Fabiato, 1975). Since it has been well documented that caffeine is a strong modulator of CICR in several preparations, it seemed appropriate that its effects are studied in the context of localized detection of $\mathrm{Ca}^{2+}$ transients.

Caffeine is an important potentiator of twitch tension in skeletal muscle that operates at concentrations in the millimolar range (Gutmann and Sandow, 1965; Sandow, 1970). The unveiling of the many factors that contribute to this action of the drug has been a topic of intense research and debate in the field of muscle excitationcontraction (EC) coupling during the past 30 years (for a review see Herrmann-Frank et al., 1999). From this literature, it has become apparent that caffeine effects in vivo may be related to the drug's ability to activate ryanodine receptor (RyR) channels in the sarcoplasmic reticulum (SR) of skeletal muscle fibers. However, there is a great discrepancy in the doses of caffeine required for the direct activation of the RyR in vitro 
(and probably in vivo), which is in the tens of millimolar range (Rousseau et al., 1988; Sitsapesan and Williams, 1990), compared with the more physiological potentiation of $\mathrm{Ca}^{2+}$ release in amphibian muscle fibers, which occurs in the sub-millimolar (up to 1 $\mathrm{mM}$ ) range (Delay et al., 1986). Without plunging into controversial topics, we want to concentrate our attention on the latter situation (frog fibers, low caffeine doses), in which the following tenets seem to apply: a) there is no substantial effects on the surface membrane or T-tubule electrical properties (Delay et al., 1986); b) there is no detectable increase in the resting free- $\mathrm{Ca}^{2+}$ level in single muscle fibers, as estimated from measurements with $\mathrm{Ca}^{2+}$ electrodes and $\mathrm{Ca}^{2+}$ indicators (Lopez et al., 1983; Delay et al., $1986)$; c) there is no effect of the forcegenerating ability of the contractile filaments (Wendt and Stephenson, 1983); d) caffeine potentiation effects on $\mathrm{Ca}^{2+}$ release are mostly reversible upon removal of the drug; and e) there is measurable shift in the voltage dependence of $\mathrm{Ca}^{2+}$ release towards negative potentials (Delay et al., 1986; Shirokova and Rios, 1996). Altogether, these results suggest that low levels of caffeine modulate EC coupling in amphibian skeletal muscle by secondarily enhancing the ability of the SR to release $\mathrm{Ca}^{2+}$, probably by increasing probability of opening of RyR channels (Rousseau et al., 1988), but without affecting the transduction mechanism at the T-SR junction. The purpose of this paper is to investigate the effects of low caffeine concentrations on the spatiotemporal properties of $\mathrm{Ca}^{2+}$ release domains during the physiological activation of the EC coupling process in order to further elucidate this drug's mechanisms of in vivo potentiation.

Preliminary results on the effects of caffeine have been presented elsewhere (Vergara et al., 2001a).

\section{METHODS}

The general methodology and technical improvements of the confocal spot detection system utilized for the experiments presented below have been described extensively elsewhere (Vergara et al., 2001b; DiFranco et al., 2002). We provide here a brief account of the major features of the confocal technique inasmuch as they are required to understand the experimental data.

\section{Muscle fiber preparation and electrophysiological methods}

Briefly, segments of cut single fibers from the dorsal head of the semitendinosus muscle from Rana catesbeiana were mounted in an inverted double Vaselinegap chamber. The fibers were stretched to 3.7-4.5 $\mu \mathrm{m}$ to prevent contraction. Two Vaseline seals isolated three segments of the fiber. The lateral segments were permeabilized with saponin $(100 \mu \mathrm{g} / \mathrm{ml} ; 1-3$ min) to allow for free exchange between the lateral pool's solution and the intracellular milieu of the central segment of the fiber. The central pool was perfused continuously with normal Ringer's solution, with or without caffeine, whereas the lateral pools contained internal solution (see below). APs were elicited by supra- threshold current pulses delivered to the muscle fiber through one lateral pool and recorded with a custom-made electronic circuit (DiFranco et al., 1999). The membrane potential of the central segment of the fiber was measured as the potential of the central pool minus the potential of the lateral pool opposite to that used for current injection. APs were filtered at $10 \mathrm{kHz}$, with an 8-pole Bessel filter (Frequency Devices, Haverhill, MA, USA) and digitized at $25-50 \mathrm{kHz}$ using a PCI-MIO-16XE-10 data acquisition board (National Instruments, Austin, TX, USA).

\section{Solutions}

Ringer's solution: $114 \mathrm{mM} \mathrm{NaCl} ; 2.5 \mathrm{mM}$ $\mathrm{KCl} ; 10 \mathrm{mM}$ MOPS-Na; $1.8 \mathrm{mM} \mathrm{CaCl}_{2}, 10$ $\mathrm{mM}$ dextrose. Isotonic high $\mathrm{K}: 110 \mathrm{mM}$ $\mathrm{K}_{2} \mathrm{SO}_{4}, 10 \mathrm{mM}$ MOPS. Internal solution: $110 \mathrm{mM}$ Aspartate-K; $20 \mathrm{mM}$ MOPS-K; 1 $\mathrm{mM} \mathrm{MgCl}_{2}, 5 \mathrm{mM} \mathrm{Na} 2$ phosphocreatine, 5 $\mathrm{mM}$ K2-ATP, 0.5 or $1 \mathrm{mM}$ EGTA, $0.1 \mathrm{mg} /$ $\mathrm{ml}$ Creatine-phosphokinase. The osmolality and $\mathrm{pH}$ of the solutions were adjusted to $250 \mathrm{mOsm} / \mathrm{kg}$ and 7.0 , respectively. Unless 
otherwise noted, the experiments were performed at $18^{\circ} \mathrm{C}$.

\section{Optical setup and stage-scanning system}

The optical system was based on an inverted epifluorescence microscope (Model IM, Zeiss, Oberkochen, Germany). In addition to the standard bright-field configuration, it could operate as a stage scanning confocal or standard fluorescence microscope. In confocal mode, the $488 \mathrm{~nm}$ line of an Argon laser (Model 95, Lexel, Freemont, CA, USA) was focused onto a 5 $\mu \mathrm{m}$ pinhole (PH-5, Newport Corporation, Irvine, CA, USA). The pinhole image was projected using a $5 \mathrm{x}$ objective through the illumination port of the microscope. A 505DRLP dichroic mirror (Omega Optical, Brattleboro, VT, USA) directed the excitation light to a $100 \mathrm{x}$ high NA oil immersion objective (Plan Fluor 100, 1.3 NA, Nikon, Japan) that focused it to a 0.8 $\mu \mathrm{m}$ spot on the preparation. The fluorescence image of the illumination spot was collected with the same lens, passed through a $515 \mathrm{~nm}$ long-pass emission filter (Omega Optical), and centered on a $50 \mu \mathrm{m}$ pinhole (04PIP013, Melles Griot, Rochester, NY, USA) used to mask the square active area $(200 \mu \mathrm{m}$ per side) of a PIN photodiode (HR008, United Detector Technology, Hawthorne, CA, USA), which served as the light detector. The photocurrent was amplified using an integrating patch-clamp unit (Axopatch 200B, Axon Instruments, Foster City, CA, USA) and filtered at $2-5 \mathrm{kHz}$ using an 8 pole Bessel filter (Frequency Devices). The optical signal and the AP were acquired simultaneously using the acquisition board described above. A shutter (22510A1S5, Vincent and Associates, Rochester, NY, USA) was used to control the illumination time of the sample.

The experimental chamber and the electronic headstage were mounted on a custom-made microscope stage. Two openloop motorized drives (860A-2, Newport) were used for coarse movement of the stage in the $\mathrm{x}$ - or $\mathrm{y}$-direction (orthogonal to the optical axis of the microscope). In addition, a high-resolution nanotranslator (Model
TSE-150, Burleigh Instruments, Inc., Fishers, NY, USA), driven by an inchworm motor with a closed-loop integral linear encoder, permitted positioning of the stage along the $\mathrm{x}$ - axis with $50 \mathrm{~nm}$ resolution. A 6000ULN controller (Burleigh Instruments) was used to drive the inchworm motor under computer control using customwritten software in G-language (Labview, National Instruments). This software also was used to control a stepper motor (ZAxis 1, Prairie Technologies, Waunakee, WI, USA), driving the focusing mechanism of the microscope (z-axis) with $500 \mathrm{~nm}$ resolution. In stage-scanning confocal mode, the specimen was moved in the $\mathrm{x}$ direction while the confocal spot remained stationary and the long axis of the muscle fiber was aligned parallel to the $\mathrm{X}$-axis of the microscope stage. The lateral (X-Y) and axial $(\mathrm{Z})$ resolution of the confocal system was determined in vitro using fluorescently labeled latex beads to be 0.3 and $0.75 \mu \mathrm{m}$, respectively (Vergara et al., 2001b).

\section{Measurement and analysis of $\mathrm{Ca} 2+-$ dependent fluorescence transients}

The salt form of the $\mathrm{Ca}^{2+}$ indicator Oregon Green 488 BAPTA-5N (OGB-5N) (Molecular Probes, Invitrogen, OR, USA) was added at $500 \mu \mathrm{M}$ concentrations to the cut ends and allowed to diffuse into the muscle fiber 45-60 minutes prior to optical measurements being started. The typical experimental protocol used to acquire localized fluorescence transients in response to a single AP stimulation of the muscle fiber and their normalization in terms of $\Delta \mathrm{F} / \mathrm{F}$ is described in detail elsewhere (Vergara et al., 2001b; DiFranco et al., 2002). The amplitude of the transients was characterized by its $(\Delta \mathrm{F} /$ $F)_{\text {peak }}$ value and its specific duration by the full duration at half maximum (FDHM).

To determine the spatial dependence of $\left[\mathrm{Ca}^{2+}\right]$ changes, the illumination spot was initially focused to within $10 \mu \mathrm{m}$ from the bottom coverslip and on a random location with respect to the fiber's sarcomere structure. Subsequently, individual fluorescent transients elicited by AP stimulation were recorded every 3-5 s from 
adjacent sites, separated by $200 \mathrm{~nm}$, along the longitudinal axis of the fiber. The combination of stretching and the use of exogenous intracellular $\mathrm{Ca}^{2+}$ buffers (OGB$5 \mathrm{~N}$ and EGTA) prevented any fiber movement, as evidenced by direct observation under the microscope and the lack of movement artifacts in the optical records.

Average variance traces $\left(\overline{\sigma^{2}}(t)\right)$ were computed from a set of $N\left(\frac{\Delta F(t)}{F}\right)_{i}$ records, and their mean $\left(\overline{\frac{\Delta F(t)}{F}}\right)$, according to the following equation:

$$
\overline{\sigma^{2}}(t)=\frac{1}{N-1} \sum_{i=1}^{N}\left(\left(\frac{\Delta F(t)}{F}\right)_{i}-\frac{\overline{\Delta F(t)}}{F}\right)^{2}
$$

These traces were further normalized by the amplitude of the $\left(\frac{\overline{\Delta F(t)}}{F}\right)$ average in order to compute the records shown in Figure 5 (see below). All calculations were performed using a commercial software package (Origin, Microcal, Northampton, MA, USA).

\section{RESULTS}

\section{Localized AP-evoked $\mathrm{Ca}^{2+}$ transients}

Figure 1A shows a family of AP-evoked fluorescence transients from a highly stretched muscle fiber (sarcomere length $=$ $4.2 \mu \mathrm{m})$ stained intracellularly with the $\mathrm{Ca}^{2+}$ indicator OGB-5N. The optical traces were recorded from 11 consecutive positions, $200 \mathrm{~nm}$ apart, along the longitudinal axis of the fiber. The scan spanned a half sarcomere, from a Z-line (trace 1) to the adjacent M-line (trace 11). Figure $1 \mathrm{C}$ is a superposition of the 11 APs that elicited the fluorescence transients. It can be observed in Figures $1 \mathrm{~A}$ and $1 \mathrm{~B}$ that the transient recorded at the $\mathrm{Z}$-line is significantly faster and larger than the one recorded at the M-line. Also, the kinetic features of the transients recorded at intermediate locations between the M- and
Z-line vary continuously from their extreme values at these positions. It should be noted that the position-dependent properties of the optical traces are not accompanied by any detectable change in the electrical records shown in Figures 1C and 1D; they are identical to within $1 \mathrm{mV}$. While the rising phases of the AP-evoked $\mathrm{Ca}^{2+}$ transients become slower as the recording position moves from the $\mathrm{Z}$ - to the M-line, their falling phases remain relatively constant. The characteristic parameters for $\mathrm{Z}$ - and $\mathrm{M}$-line $\mathrm{Ca}^{2+}$ transients were reported previously for fibers with $0.5 \mathrm{mM}$ internal [EGTA] (Vergara et al., 2001b; DiFranco et al., 2002). For experiments in fibers equilibrated with $1 \mathrm{mM}$ internal [EGTA], as is the case in Figure 1, we obtained the following $\mathrm{Z}$ - and $\mathrm{M}$-values for amplitude $\left(\Delta \mathrm{F} / \mathrm{F}_{\text {peak }}\right)$, time to peak, and FDHM: 2.06 \pm 0.03 and $0.61 \pm 0.02 ; 4.99 \pm 0.28$ and $7.49 \pm 0.36 \mathrm{~ms} ; 5.93 \pm 0.53$ and $14.23 \pm$ 1.34 , respectively. Finally, the large difference in $(\Delta \mathrm{F} / \mathrm{F})_{\text {peak }}$ between the $\mathrm{Z}$ - and M-line transients (2.1 vs . 0.61, respectively) demonstrates the existence of large intrasarcomeric $\mathrm{Ca}^{2+}$ gradients, which develop zoom after stimulation but that dissipate after $\sim 15 \mathrm{~ms}$. The gradients in $1 \mathrm{mM}$ [EGTA] are more profound and dissipate faster than previously observed for fibers equilibrated with $0.5 \mathrm{mM}$ [EGTA] (DiFranco et al., 2002)

\section{AP-evoked $\mathrm{Ca}^{2+}$ domains}

The concept of a $\mathrm{Ca}^{2+}$ domain, a localized increase in $[\mathrm{Ca} 2+]$ as a function of space and time, has been used to characterize $\mathrm{Ca}^{2+}$-entry sites in excitable cells and in presynaptic terminals of the neuromuscular junction (Chad and Eckert, 1984; DiGregorio et al., 1999; DiGregorio et al., 2001) and $\mathrm{Ca}^{2+}$-release sites in skeletal muscle fibers (Escobar et al., 1994; Vergara et al., 2001b; DiFranco et al., 2002). Figure $2 \mathrm{~A}$ is a three-dimensional plot of localized AP-evoked $\mathrm{Ca}^{2+}$ transients, as a function of the spot position, which clearly portrays the topology of the inter- and intra-sarcomeric $\mathrm{Ca}^{2+}$ dynamics involved in the formation and dissipation of $\mathrm{Ca}^{2+}$ domains in a frog 
skeletal muscle fiber. Data were obtained from a fiber with $0.5 \mathrm{mM}$ internal [EGTA] and externally bathed in Ringer solution. In this plot, which spans three sarcomeres, three defined regions - regularly spaced along the muscle fiber - can be observed where the $\left[\mathrm{Ca}^{2+}\right]$ changes reported by the fluorescence indicator are most prominent. These regions are what we call $\mathrm{Ca}^{2+}$-release microdomains. We have demonstrated
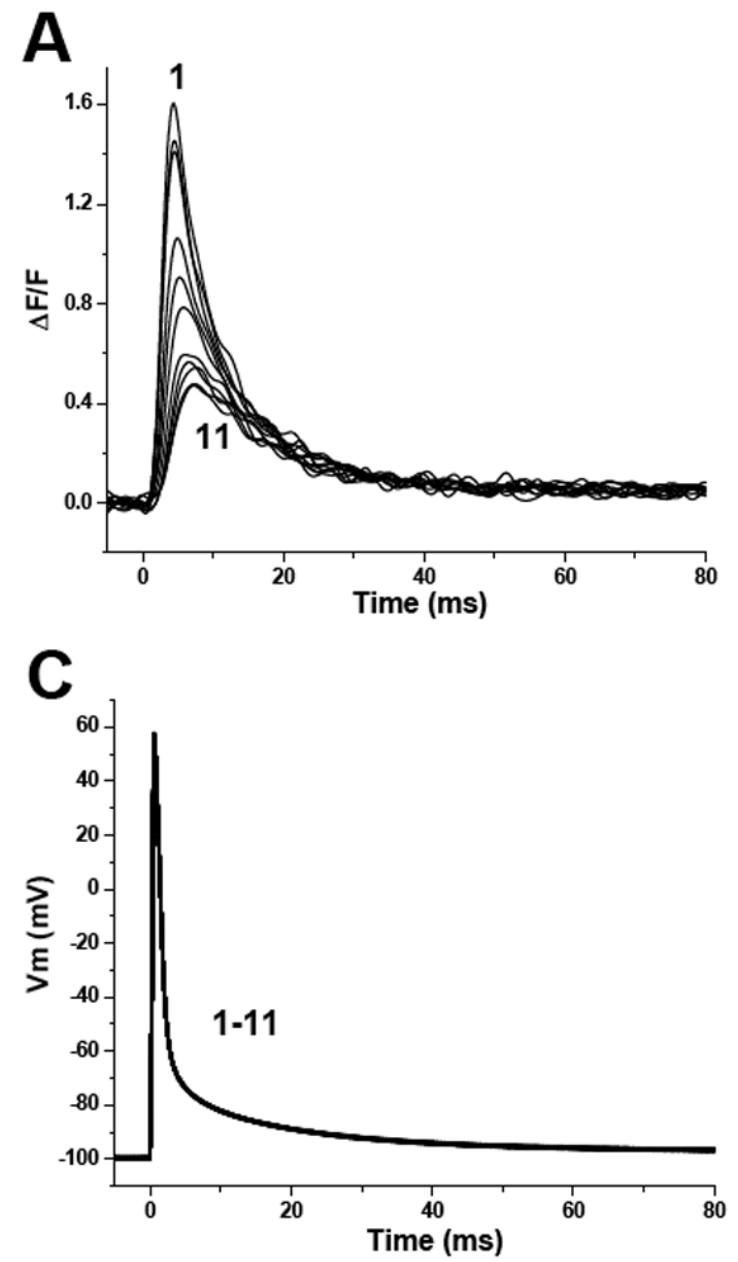

previously that they are centered where the T-SR junctions are located at the Z-line (Vergara et al., 2001b; DiFranco et al., 2002). Figure 2B shows a contour map of the same data in Figure 2A, emphasizing the spatial segregation of these local increases in $\left[\mathrm{Ca}^{2+}\right]$ and how they progress in time by decaying in amplitude and expanding along the longitudinal axis of the fiber.
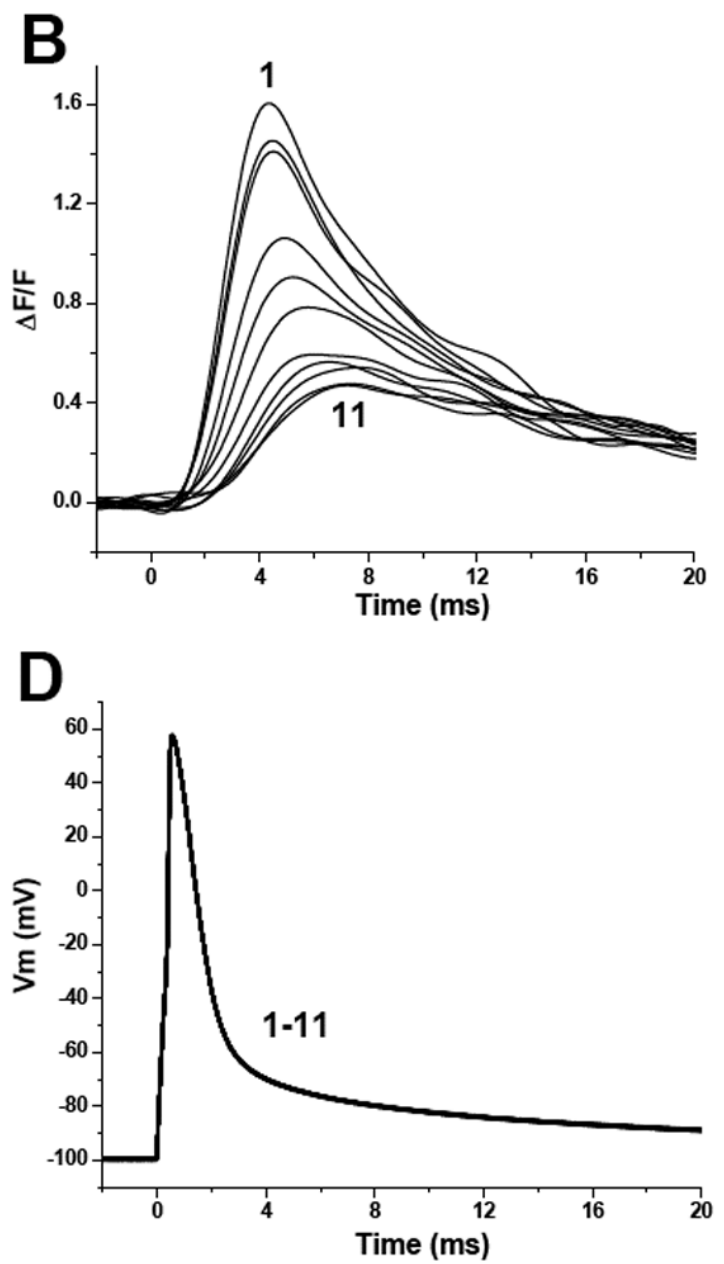

Figure 1. Positional dependence of fluorescence transients detected from a single sarcomere.

A and B: Superimposed OGB-5N $\Delta \mathrm{F} / \mathrm{F}$ transients (1 through 11) and APs recorded at 11 adjacent spot positions along a line parallel to the fiber axis are shown at two different time scales. Traces 1 and 11 correspond to transients recorded at the Z-line and M-line, respectively. C and D: APs associated with the fluorescence transients in A and B shown superimposed at two time scales. Sarcomere spacing: $4.2 \mu \mathrm{m}$; [EGTA]: $1 \mathrm{mM}$. The stimulus time correspond to $\mathrm{t}=0 \mathrm{~ms}$. 
A

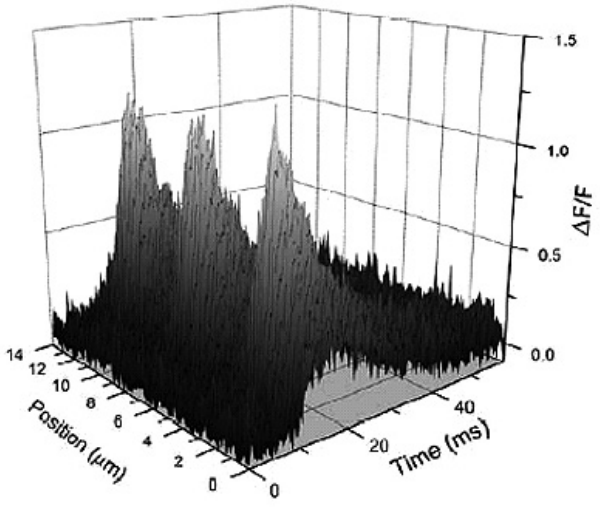

C

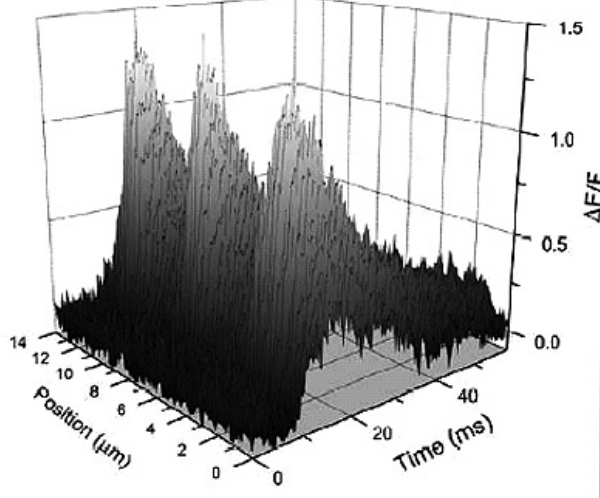

等

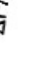

B

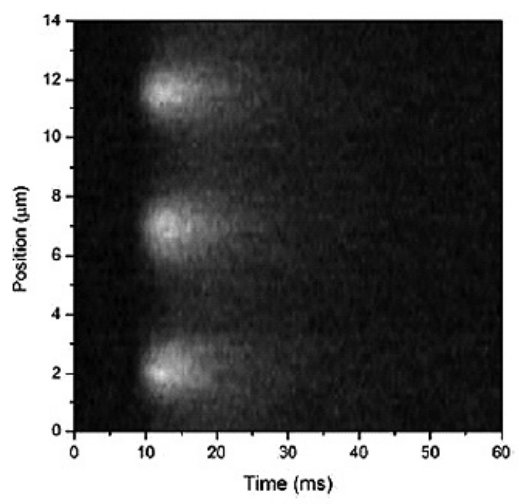

D

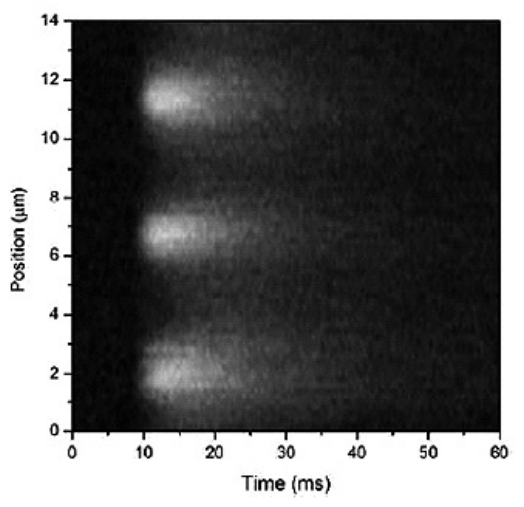

$\mathbf{F}$

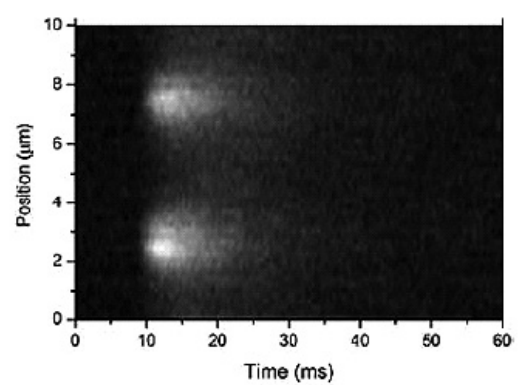

Figure 2. Effects of $0.5 \mathrm{mM}$ caffeine on $\mathrm{Ca}^{2+}$-dependent, OGB-5N fluorescence domains .

A and B: 3D and contour map created by juxtaposition of the $\mathrm{Ca}^{2+}$-dependent, OGB-5N fluorescence transients recorded at discrete positions in a muscle fiber along a distance of $\sim 14 \mu \mathrm{m}$. Panels A and B show the same three domains. C and D: 3D and contour map representations of $\mathrm{Ca}^{2+}$-dependent fluorescence domains in the presence of $0.5 \mathrm{mM}$ caffeine. $\mathbf{E}$ and $\mathbf{F}: 3 \mathrm{D}$ and contour map representations of domains obtained after removal of caffeine from the bath. Sarcomere spacing: $4.4 \mu \mathrm{m}$; [EGTA]: $0.5 \mathrm{mM}$. The grayscale palette represents 128 gray levels corresponding to $\Delta \mathrm{F} / \mathrm{F}$ values ranging from 0.3 to 1.4 . The stimulus time correspond to $\mathrm{t}=5 \mathrm{~ms}$. 
Effects of $0.5 \mathrm{mM}$ caffeine on AP-evoked $\mathrm{Ca}^{2+}$ domains

Figures $2 \mathrm{C}$ and $2 \mathrm{D}$ are three-dimensional and contour plots of three domains recorded from the same fiber, but after equilibration with $0.5 \mathrm{mM}$ caffeine in the bath. It can be observed that the $(\Delta \mathrm{F} / \mathrm{F})_{\text {peak }}$ of each domain in Figure 2C was larger in the presence of caffeine than in the control condition illustrated in Figure 2A. Furthermore, although it is clear that in 0.5 $\mathrm{mM}$ caffeine the AP-evoked domains persist for longer times, their spatial distribution apparently remains unchanged. Figures $2 \mathrm{E}$ and $2 \mathrm{~F}$ finally illustrate that the observed effects of caffeine are readily reversed upon removal of the drug from the external solution.

These qualitative observations are further confirmed in the quantitative analysis provided in Figure 3. The solid and dashed traces in Figure 3A are average $\mathrm{Z}$ line transient calculated from the three domains in Figures 2A (control) and 2C (0.5 $\mathrm{mM}$ caffeine), respectively. The comparison between these records demonstrates that caffeine induces a significant increase $(16 \% ; \mathrm{p}<0.05)$ in the amplitude of the Z-line transients. In addition, the prolongation of the $\mathrm{Ca}^{2+}$ transients by caffeine is evidenced by the significant increase in the FDHM from 10.7 to $16.5 \mathrm{~ms}$. Figure $3 \mathrm{~B}$ is a superimposition of the six APs that elicited the transients used to calculate the average Z-line transients in Figure 3A. It can be seen that they are practically identical, ruling out the possibility that the caffeine effects on the $\mathrm{Ca}^{2+}$ transients result from electrical changes in the APs. Altogether, the above observations from Z-line-localized data are concurrent with previous results reporting the effects of $0.5 \mathrm{mM}$ caffeine of frog fibers using global illumination/detection techniques and metallochromic indicators (Delay et al., 1986). This finding is interesting since it circumscribes these caffeine effects to be occurring at specific regions of the muscle fibers where the APevoked (physiological) $\mathrm{Ca}^{2+}$ release normally occurs. This observation is further confirmed by the results shown in Figures
3C and 3D, which demonstrated that the full width at half-maximum (FWHM) of domains measured isochronously at the time the Z-line transient peaks $(\sim 5 \mathrm{~ms}$ after AP stimulation) does not change in the presence of $0.5 \mathrm{mM}$ caffeine.

Changes induced by $1 \mathrm{mM}$ caffeine on APevoked $\mathrm{Ca}^{2+}$ domains

Figure 4A is a contour map of a long scan comprising 13 sarcomeres of a muscle fiber transiently exposed (for $\sim 5 \mathrm{~min}$ ) to $1 \mathrm{mM}$ caffeine. The scanning process was done as usual by advancing the spot position in 200 $\mathrm{nm}$ steps while the fiber was continuously perfused with solutions of different compositions. The scan started with the fiber in Ringer's solution and the first three domains were acquired (positions 0-12 $\mu \mathrm{m})$. Without interruption of the scanning process, the external solution was then switched to Ringer $+1 \mathrm{mM}$ caffeine. Five domains (positions 12 to $32 \mu \mathrm{m}$ ) were recorded under these conditions, and finally, the fiber was returned to Ringer's solution where the last five domains were recorded. A salient feature of the exposure to $1 \mathrm{mM}$ caffeine illustrated in Figure $4 \mathrm{~A}$ is that there is a significant prolongation of the $\mathrm{Ca}^{2+}$ domains. However, this effect is not constant while the fiber is in the presence of caffeine, but decays over time. By comparing the amplitude of the isochronal profiles before $(\Delta \mathrm{F} / \mathrm{F}=1.94 \pm$ 0.03 , Figure $4 \mathrm{~B}$ ) and during the application of caffeine $(\Delta \mathrm{F} / \mathrm{F}=1.87 \pm 0.04$, Figure $4 \mathrm{C})$, we conclude that, in contrast to what was observed at $0.5 \mathrm{mM}$, at $1 \mathrm{mM}$ caffeine does not potentiate $\mathrm{Ca}^{2+}$ release $(\mathrm{p}>0.2)$. However, in agreement with what was observed with lower doses of the drug, the $\mathrm{Ca}^{2+}$ domains were not broadened by $1 \mathrm{mM}$ caffeine since the FWHMs measured before $(1.43 \pm 0.05 \mu \mathrm{m})$ and during exposure to caffeine $(1.48 \pm 0.07 \mu \mathrm{m})$ were not significantly different $(\mathrm{p}>0.5)$. Curiously, the isochronal profiles obtained after the removal of caffeine from the bath solution (Figure 4D) have the same amplitude but are marginally narrower than those obtained before and during caffeine exposure $(\mathrm{p}=0.05)$. 

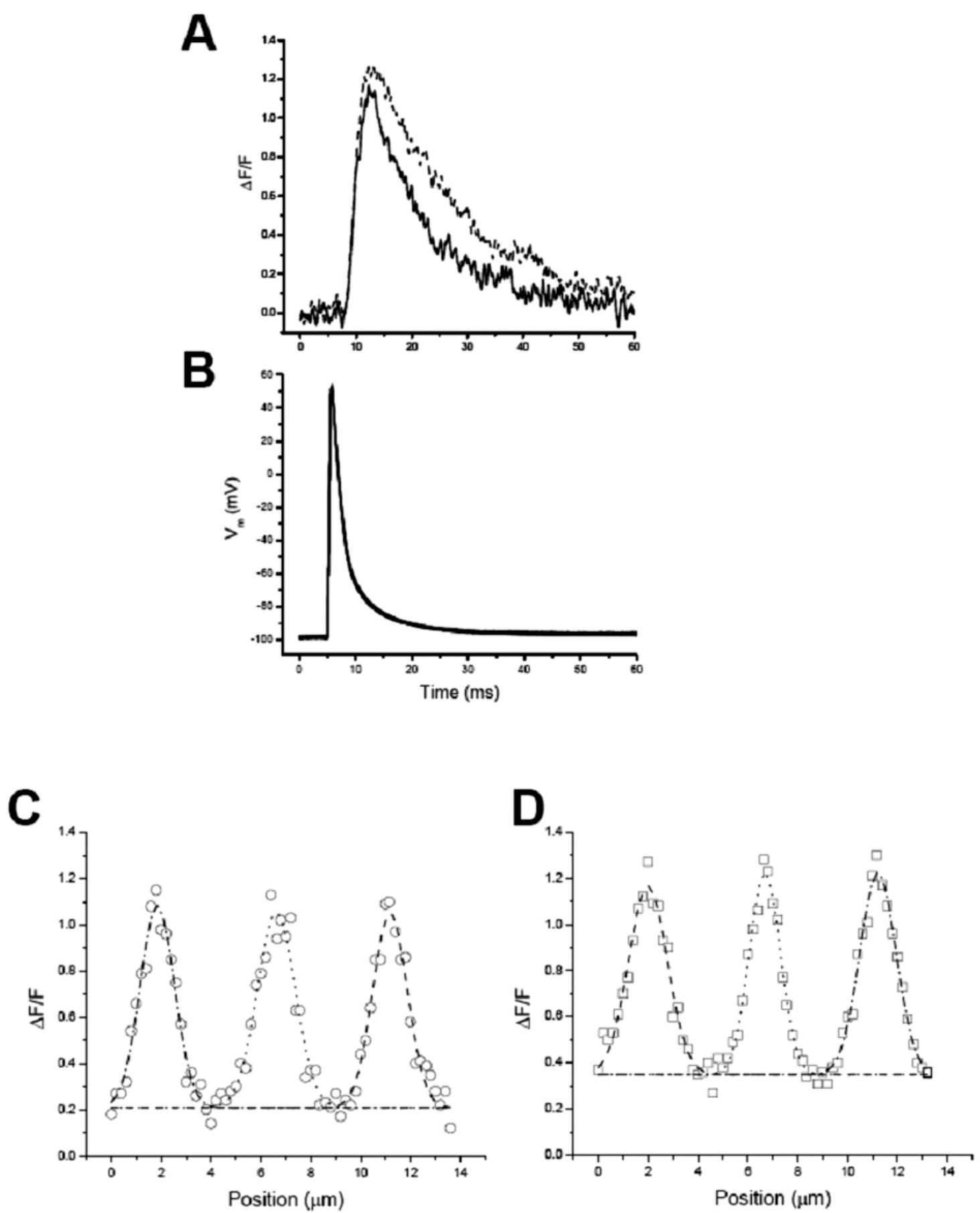

Figure 3. Effects of $0.5 \mathrm{mM}$ caffeine on Z-line transients and FWHM of $\mathrm{Ca}^{2+}$ micro-domains.

A: Each trace represents the average Z-line transient from three consecutive sarcomeres, scanned before (solid trace) and during (dashed line) the application of $0.5 \mathrm{mM}$ caffeine. B: Superposition of the six APs that elicited the Z-lines transients used to calculated the average traces shown in A. C and D: Isochronal profiles calculated at the time the Z-line transient peaks. Data were obtained before (panel C) and during (panel D) the application of caffeine. The FWHM of the domains is $1.42 \pm 0.09$ and $1.49 \pm 0.07 \mu \mathrm{m}$, for control and $0.5 \mathrm{mM}$ caffeine, respectively. The values are not significantly different $(\mathrm{p}>0.5)$. Sarcomere spacing: $4.4 \mu \mathrm{m}$; [EGTA]: $0.5 \mathrm{mM}$. The stimulus time correspond to $\mathrm{t}=5 \mathrm{~ms}$. 
A

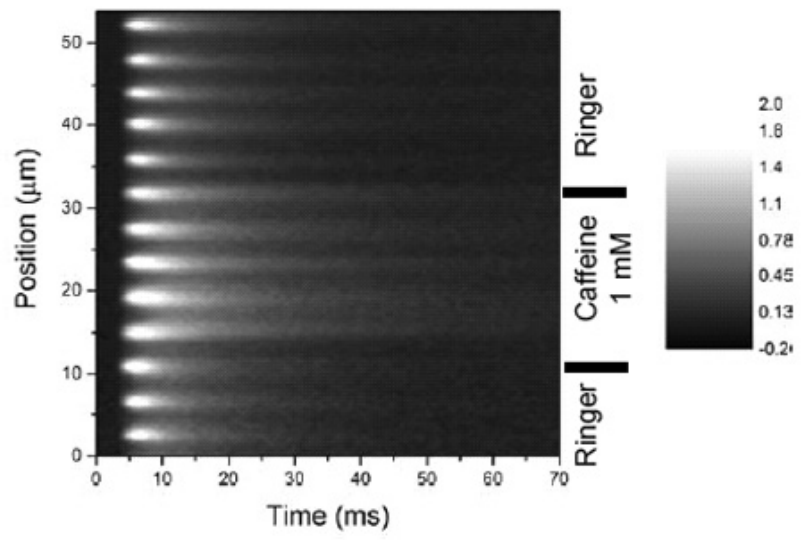

B

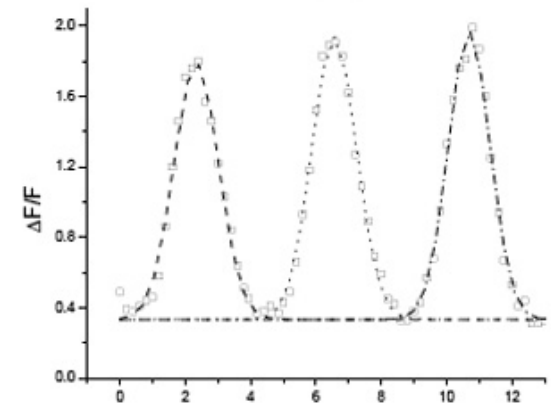

Ringer

C

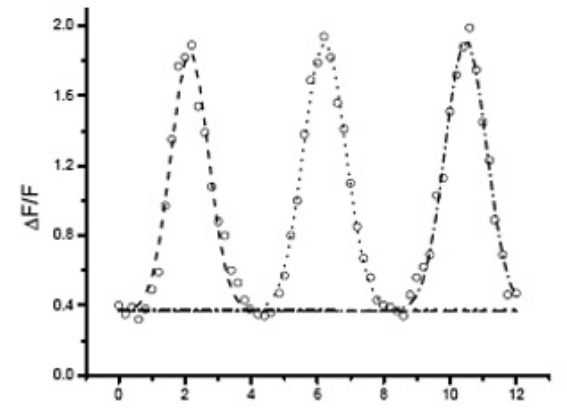

Ringer +

$1 \mathrm{mM}$ caffeine

D

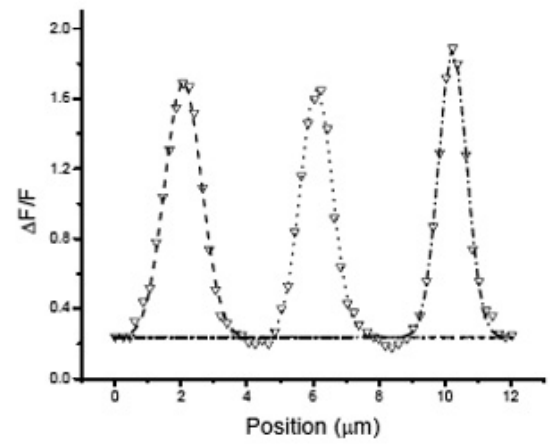

\section{Ringer}

(wash)

Figure 4. Effects of $1 \mathrm{mM}$ caffeine on $\mathrm{Ca}^{2+}$-release microdomains.

A: Contour map of a continuous scan spanning 13 sarcomeres. From the bottom up, the first three domains were obtained before the application of caffeine, the next five in the presence of caffeine, and the last five, after washing out the drug from the bath. The stimulus time corresponds to $t=0$ $\mathrm{ms}$. B to D: Plots of isochronal profiles at the point when the Z-line transients peaked. Panel B data was obtained from domains 1 to 3 in A (Ringer). Panel C data was obtained from domains 6 to 8 in A (Ringer+1 $\mathrm{mM}$ caffeine). Panel D data was obtained from domains 11 to 13 in A (Ringer). Sarcomere spacing: $4.2 \mu \mathrm{m}$; [EGTA]: $1.0 \mathrm{mM}$. 


\section{Unexpected effects of $1 \mathrm{mM}$ caffeine}

The ability to record from minute volumes inside the sarcomere permits us to report on drug effects not detectable by global detection methods. While studying the effects of $1 \mathrm{mM}$ caffeine on localized $\mathrm{Ca}^{2+}$ release, we found several unexpected phenomena, and here, we report two of them. An interesting set of observations are illustrated in Figure 5. Figures 5A and 5C show superimposed Z-line transients from two sets of sarcomeres acquired before and during exposure to caffeine, respectively. Besides confirming our observations above on the effect of $1 \mathrm{mM}$ caffeine on the amplitude and kinetics of the transients (Figure 4), these figures demonstrate that there is not too much variability among localized Z-line $\mathrm{Ca}^{2+}$ transients both under control conditions or in the presence of caffeine. These observations are further confirmed by the relatively small values of normalized average variance plotted in Figure 5E, even in the case of caffeine exposure (solid trace). In contrast, when the variability among M-line transients was investigated (Figures 5B, 5D, and 5F), the results are in sharp contrast with those for Z-line transients. Although in the absence of caffeine, M-line transients from different domains are relatively similar to each other (see Figure 5A and dotted trace in Figure $5 \mathrm{~F})$, exposure to $1 \mathrm{mM}$ caffeine dramatically increased the variability among them. This is clearly visible in the widely different kinetics and amplitudes of the five different records superimposed in Figure 5D, and quantitatively demonstrated by the significant increase in the normalized variance record (solid trace) of Figure 5F.

Another interesting result is the sporadic observation of extra-triadic $\mathrm{Ca}^{2+}$ release illustrated in Figure 6. It can be observed in the three-dimensional and contour plots (Figures 6A and 6B, respectively) that shortly after the application of caffeine (arrow in Figure 6B), an extra source of $\mathrm{Ca}^{2+}$ release appears at one side of the Zline transient of three first domains recorded after caffeine application. This $\mathrm{Ca}^{2+}$ source is not only off- centered with respect to the $\mathrm{Z}$-line, but it also was activated with a longer delay after the application of the stimulus $(t=0)$. On the other hand, as also seen in the Z-line transient, the release of the extra-junctional source is long lasting. These observations are substantiated in Figure 6C, which displays two isochronal profiles of the domains in Figure 6A: one profile was calculated at the time the Z-line transient peaked ( $\sim 5 \mathrm{~ms}$ after AP stimulation, open circles); the other was calculated $25 \mathrm{~ms}$ after AP stimulation (filled circles) when the $\left[\mathrm{Ca}^{2+}\right]$ of the three domains had subsided to basal levels in Ringer solution, but remained elevated in $1 \mathrm{mM}$ caffeine. It should be noted that the spurious $\mathrm{Ca}^{2+}$ source, seen as a secondary peak in the late isochronal profile, is located $\sim 1 \mu \mathrm{m}$ away from the Z-line (towards the M-line) and has an amplitude comparable to the fluorescence detected at that point in time at the Z-line.

\section{DISCUSSION}

The results presented here emphasize the importance of using localized detection techniques to investigate the effects of caffeine on EC coupling in skeletal muscle. Namely, some of the observations on the amplitude and kinetics of localized $\mathrm{Ca}^{2+}$ transients mimic the effects of the drug observed with global detection methods (Delay et al., 1986; Herrmann-Frank et al., 1999), but other outcomes associated with the spatiotemporal properties of $\mathrm{Ca}^{2+}$ release domains are surprising and have unfathomable implications. Thus, the finding that localized $\mathrm{Z}$-line $\mathrm{Ca}^{2+}$ transients are reversibly affected by caffeine in a concentration-dependent fashion broadly agrees with the effects reported with metallochromic indicators by Delay et al. (1986). At low concentrations $(0.5 \mathrm{mM})$, we observed potentiation (increase in peak $\Delta \mathrm{F} / \mathrm{F}$ ) and prolongation (increased FDHM) of the Z-line $\mathrm{Ca}^{2+}$ transients (Figs. 2 and 3), the same as reported by these authors for global transients. Also, at higher doses (1 $\mathrm{mM}$ in our case) the potentiation is not so obvious, but the prolongation remains 


\section{Z-line}
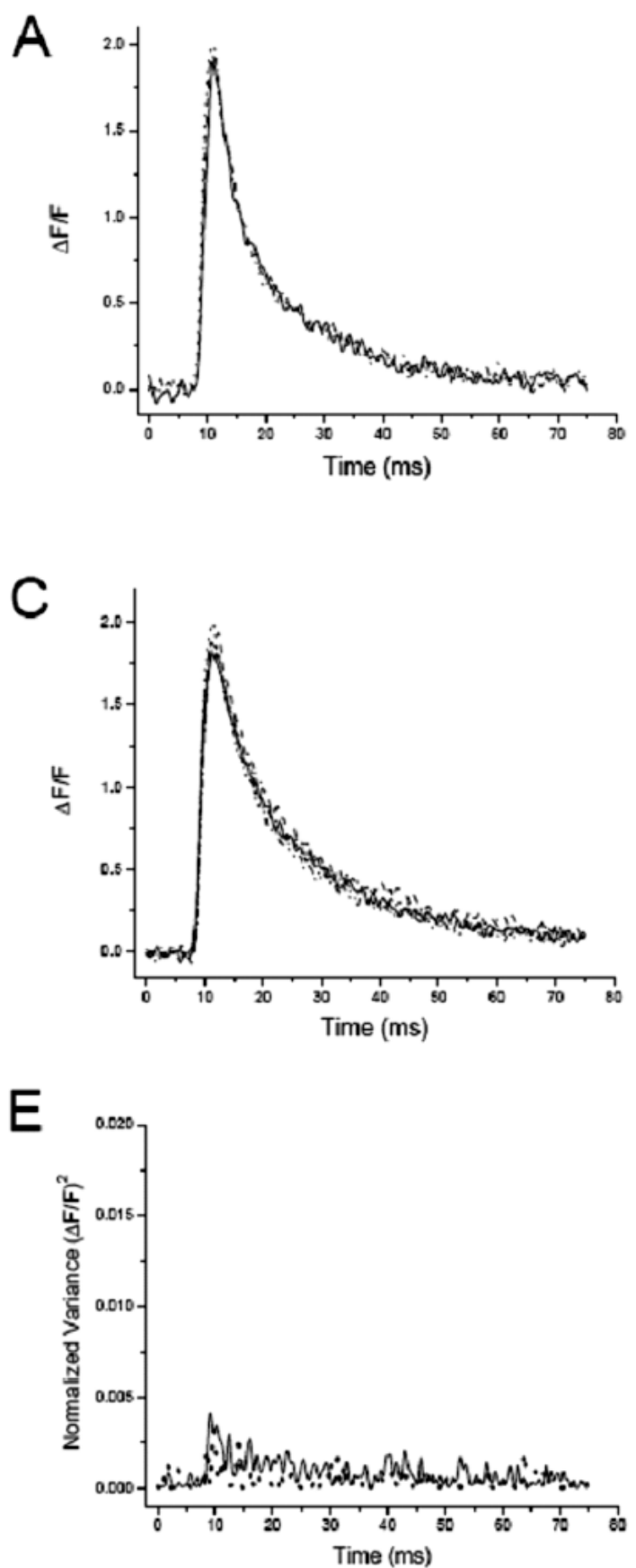

M-line
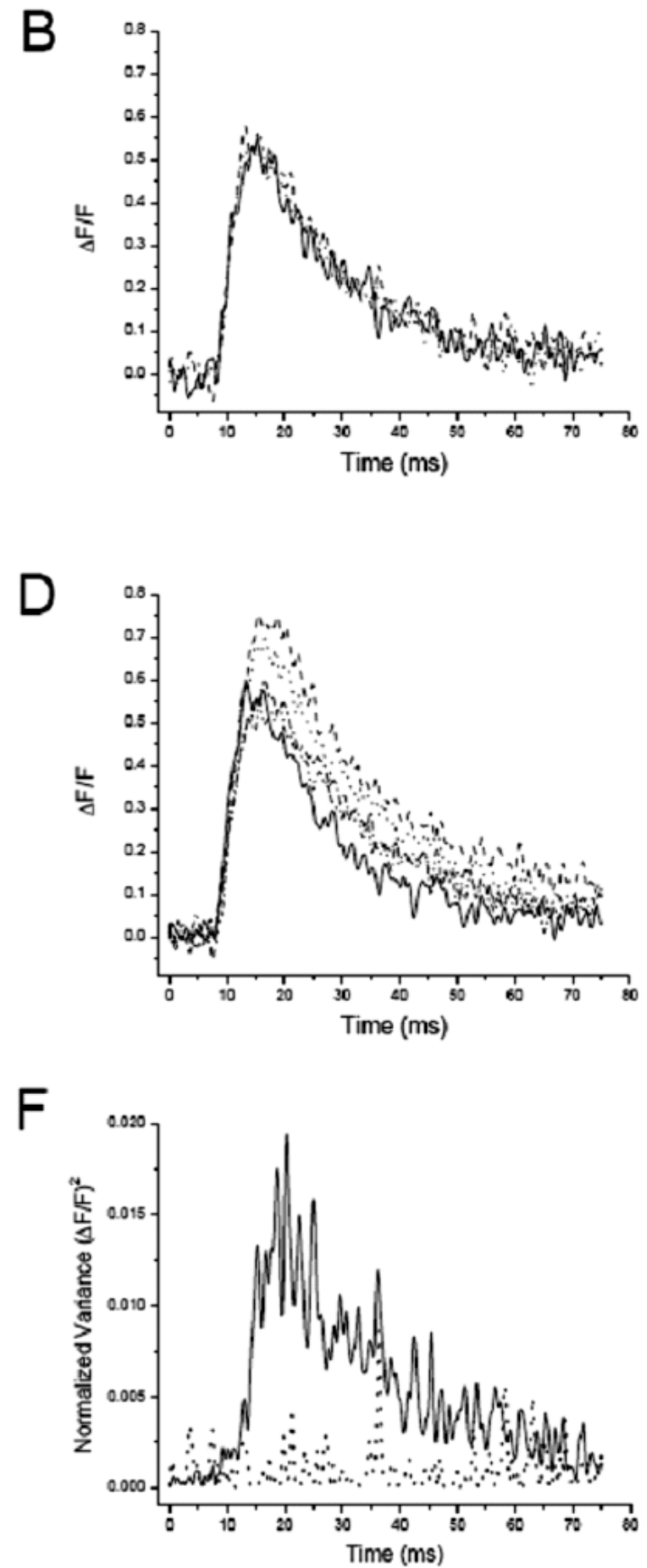

Figure 5. Caffeine-induced variance in $\mathrm{M}$-line localized $\mathrm{Ca}^{2+}$ transients.

A to D: Superimposed Z-line transients (panels A and C) and M-line transients (panels B and D) recorded before (panels $\mathrm{A}$ and $\mathrm{B}$ ) and during (panels $\mathrm{B}$ and $\mathrm{D}$ ) the application of $1 \mathrm{mM}$ caffeine. Note the different $\Delta \mathrm{F} / \mathrm{F}$ scales for $\mathrm{Z}$ - and $\mathrm{M}$-line transients. $\mathbf{E}$ and $\mathbf{F}$ : Normalized average variance calculated from $\Delta \mathrm{F} / \mathrm{F}$ records obtained before (dotted traces) and during (solid traces) the application of caffeine. Data for $\mathrm{E}$ and $\mathrm{F}$ was calculated from Z- and M-line transients, respectively. Sarcomere spacing: $4.2 \mu \mathrm{m}$; [EGTA]: $1 \mathrm{mM}$. The stimulus time correspond to $\mathrm{t}=5 \mathrm{~ms}$. 

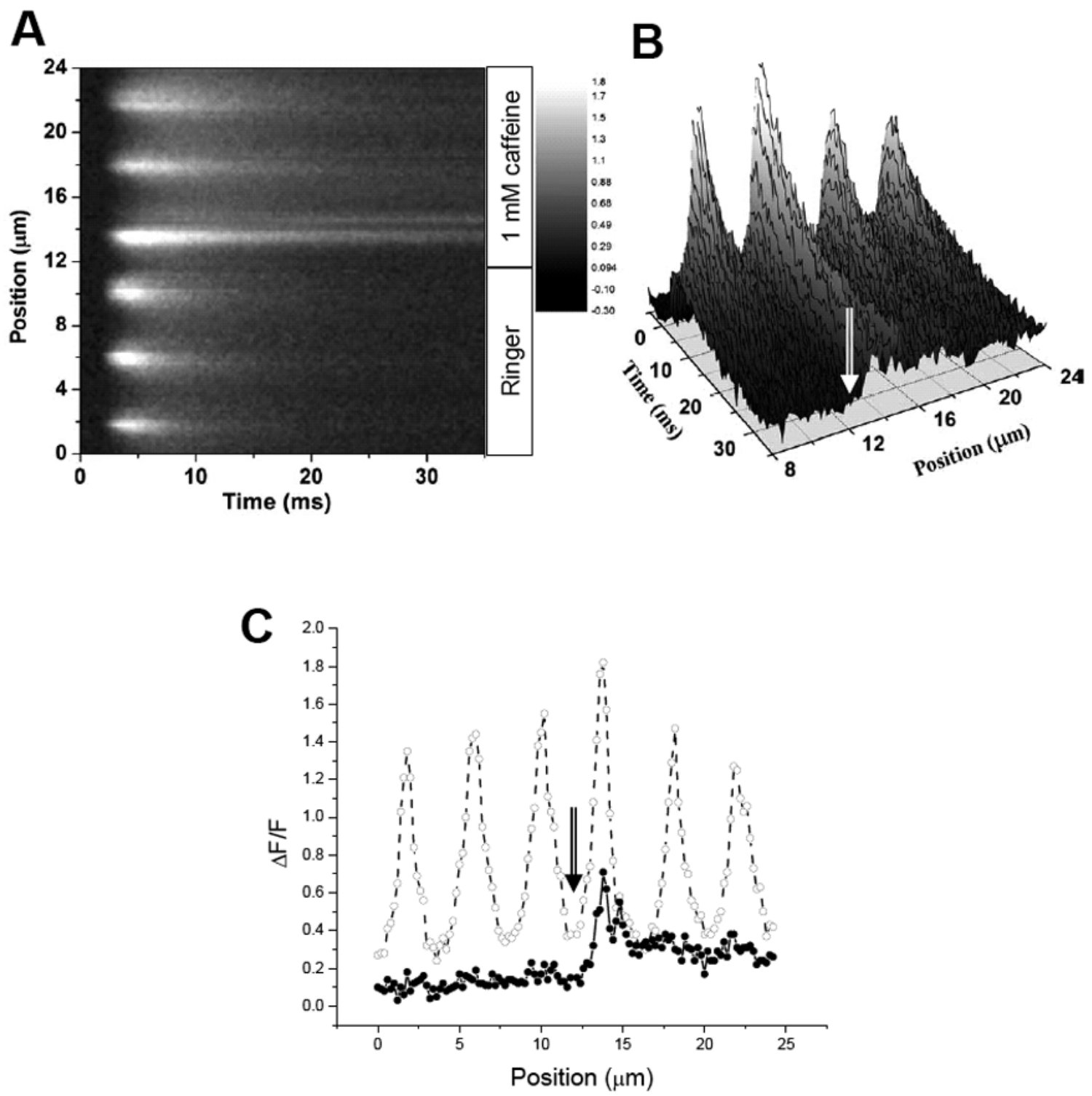

Figure 6. Extra-junctional $\mathrm{Ca}^{2+}$ release activated by $1 \mathrm{mM}$ caffeine.

A: Contour map of a continuous scan spanning 6 sarcomeres. B: 3D plot of the upper four sarcomeres shown in panel $\mathrm{A}$. The point of caffeine application is indicated by the white arrow. The stimulus time in panels A and B correspond to $t=0 \mathrm{~ms}$. C: Isochronal plots obtained at the time when the Z-line transient peaks (open circles) and $24 \mathrm{~ms}$ after stimulation (filled circles). Sarcomere spacing: $4.1 \mu \mathrm{m}$; [EGTA]: $0.5 \mathrm{mM}$.

(Figs. 4 and 5). The interesting consequences of the current observations of caffeine effects on localized Z-line transients is that they arise from highly circumscribed regions of the sarcomere where the sources of $\mathrm{Ca}^{2+}$ release are located (triads), thus providing a closer link between caffeine effects in vivo and in vitro observations of an increased open probability of the RyR channel (Rousseau et al., 1988).

It is curious that the caffeine effects on Z-line transients was not accompanied by either an increased fluctuation in their amplitudes, nor by an expansion in the FWHM of the $\mathrm{Ca}^{2+}$ release domains (Figs. 2 to 4) as would be expected from a caffeineinduced sensitization of the RyR channels 
to $\mathrm{Ca}^{2+}$ (Rousseau et al., 1988). This is important since the enhancement of CICR by caffeine traditionally has been proposed as a mechanism of $\mathrm{Ca}^{2+}$ potentiation by the drug (Herrmann-Frank et al., 1999). What is even more surprising is that, at moderate concentrations $(1 \mathrm{mM})$, caffeine was responsible for striking fluctuations in the amplitude of localized transients detected at the M-lines of the muscle fibers (Fig. 5), arguably the farthest away from the expected location for $\mathrm{Ca}^{2+}$ release channels (Z-line). One way to reconcile these observations with the current understanding of EC coupling in amphibian skeletal muscle is that these doses of caffeine may affect the sequestration of $\mathrm{Ca}^{2+}$ by the $\mathrm{Ca}^{2+}$ ATPase, reportedly located preferentially in this region of the sarcomere (Peachey, 1965; Connolly et al., 1971).

Another tantalizing result was that in the presence of $1 \mathrm{mM}$ caffeine, extrajunctional sources of $\mathrm{Ca}^{2+}$ release were found occasionally (Fig. 6), again in regions of the sarcomere as far as $1 \mu \mathrm{m}$ away from the Z-line. The presence of these sources of $\mathrm{Ca}^{2+}$ release may be related to the large fluctuations seen at the M-line, but they have a more discrete appearance and are more infrequently observed than the latter. Interestingly, these extra-junctional $\mathrm{Ca}^{2+}$ sources resemble what would be expected for a $\mathrm{Ca}^{2+}$ spark-type of release (as seen with a low affinity $\mathrm{Ca}^{2+}$ indicator), which frequency of appearance reportedly has been enhanced by caffeine exposure in amphibian muscle fibers (Gonzalez et al., 2000).

\section{ACKNOWLEDGEMENTS}

This work was supported by National Institutes of Health grants AR47664 and GM074706 and a Grant in Aid from the Muscular Dystrophy Association.

\section{REFERENCES}

CHAD JE, ECKERT R (1984) Calcium domains associated with individual channels can account for anomalous voltage relations of $\mathrm{Ca}$-dependent responses. Biophys $\mathrm{J}$ 45: 993-999
CONNOLLY R, GOUGH W, WINEGRAD S (1971) Characteristics of the isometric twitch of skeletal muscle immediately after a tetanus. A study of the influence of the distribution of calcium within the sarcoplasmic reticulum on the twitch. J Gen Physiol 57: 697-709

DELAY M, RIBALET B, VERGARA J (1986) Caffeine potentiation of calcium release in frog skeletal muscle fibres. J Physiol 375: 535-559

DIFRANCO M, NOVO D, VERGARA JL (2002) Characterization of the calcium release domains during excitation-contraction coupling in skeletal muscle fibres. Pflugers Arch 443: 508-519

DIFRANCO M, QUINONEZ M, DIGREGORIO DA, KIM AM, PACHECO R, VERGARA JL (1999) Inverted double-gap isolation chamber for high-resolution calcium fluorimetry in skeletal muscle fibers. Pflugers Arch 438: 412-418

DIGREGORIO DA, NEGRETE O, JEROMIN A, PENG HB, VERGARA JL (2001) Contact-dependent aggregation of functional $\mathrm{Ca}^{2+}$ channels, synaptic vesicles and postsynaptic receptors in active zones of a neuromuscular junction. Eur J Neurosci 14: 533-546

DIGREGORIO DA, PESKOFF A, VERGARA JL (1999) Measurement of action potential-induced presynaptic calcium domains at a cultured neuromuscular junction. J Neurosci 19: 7846-7859

ENDO M, TANAKA M, OGAWA Y (1970) Calcium induced release of calcium from the sarcoplasmic reticulum of skinned skeletal muscle fibres. Nature 228: $34-36$

ESCOBAR AL, MONCK JR, FERNANDEZ JM, VERGARA JL (1994) Localization of the site of $\mathrm{Ca}^{2+}$ release at the level of a single sarcomere in skeletal muscle fibres. Nature 367: 739-741

FABIATO A, FABIATO F (1975) Contractions induced by a calcium-triggered release of calcium from the sarcoplasmic reticulum of single skinned cardiac cells. J Physiol (Lond) 249: 469-495

GONZÁLEZ, A, KIRSCH WG, SHIROKOVA N, PIZARRO G, BRUM G, PESSAH IN, STERN MD, CHENG H, RIOS E (2000) Involvement of multiple intracellular release channels in calcium sparks of skeletal muscle. Proc Natl Acad Sci USA 97: 43804385

GUTMANN E, SANDOW A (1965) Caffeine-induced contracture and potentiation of contraction in normal and denervated rat muscle. Life Sci 4: 1149-1156

HERRMANN-FRANK A, LUTTGAU HC, STEPHENSON DG (1999) Caffeine and excitation-contraction coupling in skeletal muscle: A stimulating story. J Muscle Res Cell Motil 20: 223-237

KIM AM, VERGARA JL (1998) Supercharging accelerates T-tubule membrane potential changes in voltage clamped frog skeletal muscle fibers. Biophys J 75: 2098-2116

LÓPEZ JR, ÁlAMO L, CAPUTO C, DIPOLO R, VERGARA JL (1983) Determination of ionic calcium in frog skeletal muscle fibers. Biophys J 43: 1-4

NOVO D, DIFRANCO M, VERGARA JL (2003) Comparison between the predictions of diffusionreaction models and localized $\mathrm{Ca}^{2+}$ transients in amphibian skeletal muscle fibers. Biophys J 85: 10801097

PEACHEY LD (1965) The sarcoplasmic reticulum and transverse tubules of the frog's sartorius. J Cell Biol 25: Suppl: 209-231

RÍOS E, PIZARRO G (1991) Voltage sensor of excitationcontraction coupling in skeletal muscle. Physiol Rev 71: 849-908 
ROUSSEAU E, LADINE J, LIU QY, MEISSNER G (1988) Activation of the $\mathrm{Ca}^{2+}$ release channel of skeletal muscle sarcoplasmic reticulum by caffeine and related compounds. Arch Biochem Biophys 267: 75-86

SANDOW A (1970) Skeletal muscle. Annu Rev Physiol 32: $87-138$

SHIROKOVA N, RIOS E (1996) Activation of $\mathrm{Ca}^{2+}$ release by caffeine and voltage in frog skeletal muscle. J Physiol 493: 317-339

SITSAPESAN R, WILLIAMS AJ (1990) Mechanisms of caffeine activation of single calcium-release channels of sheep cardiac sarcoplasmic reticulum. J Physiol 423: 425-439
VERGARA JL, DIFRANCO M, NOVO D (2001a) Confocal study of the effects of caffeine on calcium release elicited by action potential stimulation. Biophys J 80: 331a

VERGARA JL, DIFRANCO M, NOVO D (2001b) Dimensions of calcium release domains in frog skeletal muscle fibers. Proceedings of SPIE 4259: 133-143

WENDT IR, STEPHENSON DG (1983) Effects of caffeine on Ca-activated force production in skinned cardiac and skeletal muscle fibres of the rat. Pflugers Arch 398: $210-216$ 
